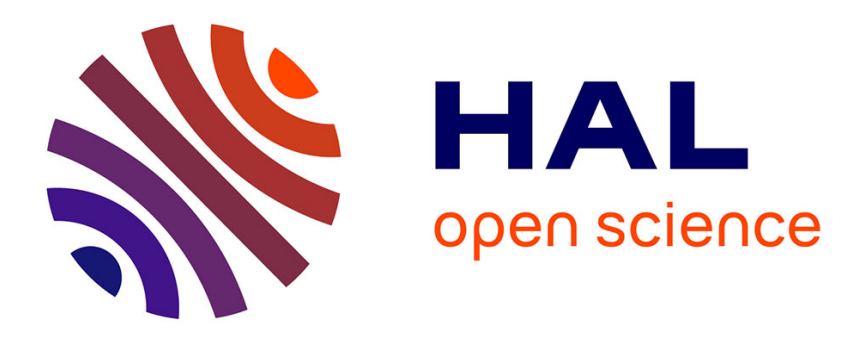

\title{
Network Neutrality: Modeling and Challenges and its Impact on Clouds
}

\author{
Bruno Tuffin
}

\section{To cite this version:}

Bruno Tuffin. Network Neutrality: Modeling and Challenges and its Impact on Clouds: Keynote Talk. GECON 2017 - 14th International Conference on Economics of Grids, Clouds, Systems \& Services, Sep 2017, Biarritz, France. hal-01634382

\section{HAL Id: hal-01634382 \\ https://hal.inria.fr/hal-01634382}

Submitted on 14 Nov 2017

HAL is a multi-disciplinary open access archive for the deposit and dissemination of scientific research documents, whether they are published or not. The documents may come from teaching and research institutions in France or abroad, or from public or private research centers.
L'archive ouverte pluridisciplinaire HAL, est destinée au dépôt et à la diffusion de documents scientifiques de niveau recherche, publiés ou non, émanant des établissements d'enseignement et de recherche français ou étrangers, des laboratoires publics ou privés. 


\title{
Network Neutrality: Modeling and Challenges and its Impact on Clouds
}

\author{
Bruno Tuffin \\ Inria \\ Campus Universitaire de Beaulieu \\ 35042 Rennes Cedex, France \\ http://www.irisa.fr/dionysos/pages_perso/tuffin/Tuffin_en.htm \\ bruno.tuffin@inria.fr
}

\begin{abstract}
Network neutrality has been a very sensitive topic of discussion all over the world. During this talk, we will first introduce the elements of the debate and introduce how the problem can be modeled and analyzed through game theory. With an Internet ecosystem much more complex now than the simple delivery chain Content-ISP-User, we will in second step highlight how neutrality principles can be bypassed in various ways without violating the rules currently evoked in the debate, for example via CDNs, or via search engines which can affect the visibility and accessibility of content. We describe some other grey zones requiring to be dealt with and spend some time on discussing the (potential) implications for clouds.
\end{abstract}

Keywords: Network Economics, Game Theory, Network Neutrality, Content Delivery Networks, Cloud Computing, Search Engines

This keynote talk is mostly based on joint works with Patrick Maillé, Pierre L'Ecuyer, Nicolas Stier, and Gwendal Simon.

Network (non) neutrality has become a very hot topic in the past few years $[6,11]$, at the same time from political, economic, and daily-life points of view, because it may refashion the Internet business model and in general the telecommunications vision and future. In short, the dispute started in the 2000s between Internet service providers (ISPs) and major content providers (CPs). ISPs were, and somewhat still are, complaining about big CPs having their resourceconsuming traffic flowing through their networks and not paying any fee for that, while CPs take is an increasing part of the total network-related revenue. As a consequence, ISPs were threatening CPs to cut their access to the network, or at least to downgrade their quality of service, if they were not accepting to pay. This raised a lot of protests, from those CPs but also from user associations, concerned about the change of philosophy of the Internet it would lead to, and the violation of the neutrality principle, stating that all consumers are entitled to reach meaningful content, and that packets should not be differentiated. The 
underlying question is whether the current telecommunications business model should be sustained, with the transition of the Internet from the initial interconnection of cooperative universities to now revenue-seeking and now often non-cooperative actors. This led to public consultations launched worldwide, and set of recommendations from regulators.

Our goals during this presentation are manyfold:

1. Introduce the debate, its history and the pros and cons of neutrality, according to its proponents and opponents (following $[7,10]$ ).

2. Describe how game theory [12] can be used to design and analyze mathematical models illustrating potential outcomes of interactions between Internet actors, and leading sometimes to counter-intuitive results. Some questions we can answer are, among others: i) Is neutrality or non neutrality beneficial to Internet actors and to society? ii) Is regulation needed to drive to a "good" outcome, and what level of regulation is required? Two illustrative models we will introduce are the following.

- In [3], we present a model with ISPs providing direct connectivity to a fixed proportion of the content, and competing for end users. Users choose their ISP based on price. Three connectivity options between ISPs are studied and compared: peering between the ISPs, no transfer of traffic between ISPs (cut transmission with as a consequence exclusivities in terms of content), and volume-based paid transit. From our analysis, the "no transfer" option does not benefit to anybody. Also, compared to peering, paid transit avoids a price war for end users when the price sensitivity of users is high. A suggested rule with minimal regulation is to let the ISPs choose transit prices with the threat to impose peering in case no agreement is reached; then user welfare is close to maximal while still leaving some decision space to ISPs.

- Another type of model in $[1,2]$ deals with the case of competitive ISPs in front of a (quasi-)monopolistic CP, a situation barely studied while relevant in practice, and a topic of complain from ISPs. Thanks to game theory again, it can be illustrated that, surprisingly, side payments are not always profitable for ISPs, and can even be beneficial to the CP. A computable level of side payments can also maximize social or user welfare, but the neutral case is the most suitable to avoid disparities between ISPs revenues.

3. Extend the debate. The network neutrality debate is solely based on the supply chain

$$
\text { CP - ISP - users. }
$$

In other words, users want to access the CP and the ISP is the intermediary. But the Internet ecosystem has become much more complex with a lot of other actors serving as intermediaries between content and users [9]: we can mention Content Delivery Networks (CDNs) or cloud providers, service providers such as search engines or web portals sometimes necessary to reach pieces of content, etc. All those providers act as intermediaries who can favor 
a service in competition with others, sometimes with financial compensation. When side payments are forbidden, ISPs could even differentiate services at a CDN or portal level by vertically integrating those services, without breaching the current neutrality principle according to which all packets are treated equally within the network. Our claim is that net neutrality debate should probably be extended to all actors involved in the Internet delivery chain.

- In $[4,8]$, we have analyzed the impact of a revenue-maximizing CDN on end-users, network providers and content providers, and compared it with a neutral behavior in order to see if regulation would need to be introduced. When there is competition between CPs, it is illustrated in [4] that an optimal pricing and caching strategy from the CDN can be unfair: a big $\mathrm{CP}$ can harm a small one by paying more. In [8], it is also shown that a CDN can also influence competition between ISPs: an ISP can harm the other by "financially welcoming" the CDN.

- In [5], we have determined the optimal ranking policy for a search engine as a trade-off between short-term revenue (based on the potential immediate gain from high-ranked links) and long-term revenue (based on the satisfaction of users due to the relevance of the ranking). A non-neutral search engine can impact innovation non-neutrality impacts innovation. A revenue-oriented search engine may indeed deter innovation at the content level due to lack of visibility. Search biased search engines have been highlighted and have induced the so-called search neutrality debate, but our claim is that it could maybe be encompassed in a more general neutrality debate.

4. Discuss more recent issues such as zero rating. Zero rating in wireless subscription plans consists in not counting an application in data caps. Should it be allowed to attract customers? Can we authorize sponsored data, where a service/content provider can pay for the transfer of data accessed by users so that they are not included in data caps? Is it against the net neutrality principle even if packets are treated the same at network level? Is it bad for customers and does it hurt competition? It is the type of questions regulators are currently investigating.

5. Discuss the implications of neutrality or non-neutrality for clouds. A nonneutral network could lead to less accessible cloud services, because requiring payments from users (through access using their data caps), or side payments from cloud providers. Neutrality is therefore central for cloud providers. But could for the other side cloud services unfairly differentiate services, and could this be against innovation at the content level? What about a vertical integration of cloud services by CPs or ISPs? Those questions could ignite an interesting and surely vivid and sensitive discussion within the GECON community. 


\section{References}

1. Boussion, F., Maillé, P., Tuffin, B.: Net neutrality debate: Impact of competition among ISPs. In: Proceedings of the Fourth International Conference on COMmunication Systems and NETworkS (COMSNETS). Bangalore, India (2012)

2. Coucheney, P., Maillé, P., Tuffin, B.: Impact of reputation-sensitive users and competition between ISPs on the net neutrality debate. IEEE Transactions on Network and Service Management 10(4), 425-433 (2013)

3. Coucheney, P., Maillé, P., Tuffin, B.: Network neutrality debate and ISP interrelations: Traffic exchange, revenue sharing, and disconnection threat. Netnomics 1(3), 155-182 (2014)

4. Gourdin, G., Maillé, P., Simon, G., Tuffin, B.: The economics of CDNs and their impact on service fairness. IEEE Transactions on Network and Service Management 14(1), 22-33 (2017)

5. L'Ecuyer, P., Maillé, P., Stier-Moses, N., Tuffin, B.: Revenue-maximizing rankings for online platforms with quality-sensitive consumers. Operations Research 65(2), 408-423 (2017)

6. Lenard, T., May, R.E.: Net Neutrality or Net Neutering: Should Broadband Internet Services be Regulated. Springer (2006)

7. Maillé, P., Reichl, P., Tuffin, B.: Internet governance and economics of network neutrality. In: Hadjiantonis, A., Stiller, B. (eds.) Telecommunications Economics Selected Results of the COST Action IS0605 EconTel, pp. 108-116. Lecture Notes in Computer Science 7216, Springer Verlag (2012)

8. Maillé, P., Simon, G., Tuffin, B.: Impact of revenue-driven CDN on the competition among network operators. In: Proceedings of CNSM (2015)

9. Maillé, P., Simon, G., Tuffin, B.: Toward a net neutrality debate that conforms to the 2010s. IEEE Communications Magazine 54(3), 94-99 (2016)

10. Maillé, P., Tuffin, B.: Telecommunication Network Economics: From Theory to Applications. Cambridge University Press (2014)

11. Odlyzko, A.: Network neutrality, search neutrality, and the never-ending conflict between efficiency and fairness in markets. Review of Network Economics 8(1), 40-60 (2009)

12. Osborne, M., Rubinstein, A.: A Course in Game theory. MIT Press (1994) 